Araştırma Makalesi / Research Article, Doğ Afet Çev Derg, 2020; 6(2): 258-267, DOI: 10.21324/dacd.602385

\title{
Uluabat Gölü Noktasal Kirletici Kaynaklar ve Kirlilik Yükleri
}

\author{
Saadet Hacısalihoğlu1, ${ }^{*}$, Feza Karaer² \\ ${ }^{1}$ Bursa Teknik Üniversitesi, Mühendislik ve Doğa Bilimleri Fakültesi, Çevre Mühendisliği Bölümü, Bursa. \\ ${ }^{2}$ Bursa Uludağ Üniversitesi, Mühendislik Fakültesi, Çevre Mühendisliği Bölümü, Bursa.

\section{Özet}

Bu çalışmada Uluabat Gölü havzasında bulunan noktasal kirletici kaynaklara ait debi değerleri ve kirlilik yükleri, A $\breve{g} u s t o s ~ 2013-$ Temmuz 2014 dönemlerini kapsayan süreçte, 12 ay boyunca, 4 farklı örnekleme noktasinda izlenmiş ve parametrelerin mekânsal ve zamansal değişimleri irdelenmiştir. İzlenen parametreler; askıda katı madde (AKM), kimyasal oksijen ihtiyacı (KOI), biyolojik oksijen ihtiyacr (BOI), amonyum azotu $\left(\mathrm{NH}_{4}-\mathrm{N}\right)$, nitrat azotu $\left(\mathrm{NO}_{3}-\mathrm{N}\right)$, toplam azot $(\mathrm{TN})$, fosfat fosforu $\left(\mathrm{PO}_{4}-\mathrm{P}\right)$ ve toplam fosfor $(\mathrm{TP})$ parametreleridir. Çalışma sonucunda, Mustafakemalpaşa Çayı'nın (MKP Çayı)ortalama debi değerinin $8.91 \mathrm{~m}^{3} / \mathrm{sn}$ ve Kocasu Çayı'nın ise $19.72 \mathrm{~m}^{3} / \mathrm{sn}$ olduğu tespit edilmiştir. Bulunan ortalama debi değerlerinin diğer noktasal kaynaklara göre yüksek olduğu gözlenmiştir. Akçalar Deresi en düşük debiye sahip noktasal kaynak olup ortalama debisi $0.03 \mathrm{~m}^{3} / \mathrm{sn}$ 'dir. Göle giriş akarsuyu olan MKP Çayı'nın göle yüksek miktarda kirlilik taşıdığı tespit edilmiştir. Kirlilik yükleri değerlendirildiğinde Akçalar Deresi'nin göle en az kirletici yükü tașıdığl (TN:19.6 ton/yll; TP:0.3 ton/yll; KOI:74 ton/yll; BOI:50.5 ton/yll; AKM:41.4 ton/yll), Uluabat pompa istasyonunun ise en çok kirletici yükü (TN:333.6 ton/yll; TP:5.3 ton/yll; KOI:1570 ton/yll; BOI:662.5 ton/yll; AKM:368.4 ton/yll) taşıdı̆̆ tespit edilmiştir.

\section{$\underline{\text { Anahtar Sözcükler }}$}

Kirletici Yükü, Noktasal Kaynak, Uluabat Gölü

\section{Lake Uluabat Point Pollutant Sources and Pollution Loads}

\begin{abstract}
In this study, flow values and pollution loads of point pollutant sources in Uluabat Lake basin were monitored in 4 different sampling points for 12 months in August 2013-July 2014 period and spatial and temporal changes of parameters were examined. The monitored parameters were suspended solids (SS), chemical oxygen demand (COD), biological oxygen demand (BOD), ammonium nitrogen $\left(\mathrm{NH}_{4}-\mathrm{N}\right)$, nitrate nitrogen $\left(\mathrm{NO}_{3}-\mathrm{N}\right)$, total nitrogen $(\mathrm{TN})$, phosphate phosphorus $\left(\mathrm{PO}_{4}-\mathrm{P}\right)$ and total phosphorus $(\mathrm{TP})$ parameters. As a result of the study, the average flow rate of Mustafakemalpaşa Stream (MKP Stream) was found to be $8.91 \mathrm{~m}^{3} / \mathrm{sec}$ and Kocasu Stream was $19.72 \mathrm{~m}^{3} / \mathrm{sec}$. It was observed that the average flow rate values were higher than other point sources. Akçalar Creek is the point source with the lowest flow rate and the average flow rate is $0.03 \mathrm{~m} / \mathrm{sec}$. It was found that MKP Stream, which is the inlet stream to the lake, carries a high amount of pollution to the lake. When the pollution loads were evaluated, it was found that Akçalar Creek carries the least pollutant (TN:19.6 tons/year; TP:0.3 tons/year; KOI:74 tons/year; BOI:50.5 tons/year; AKM:41.4 tons/year), and Uluabat pumping station has the highest pollution load (TN:333.6 tons/year; TP:5.3 tons/year; KOI:1570 tons/year; BOI:662.5 tons/year; AKM:368.4 tons/year).
\end{abstract}

Keywords

Pollution Load, Point Source, Lake Uluabat

\section{Giriş}

Sulak alanlar; ekonomik öneme sahip olma, su kuşlarına yaşama ortamı sağlama, nadir görülen veya endemik olan çok sayıda bitki ve hayvan türlerinin barınmasına imkan sağlama, su taşkınlarını önleme, kıyı şeridi stabilizasyonu, tarım için gerekli su seviyesini koruma, suyun depolanmasını sağlama, suyu temizleme ve rekreasyon imkanları sağlama gibi birçok işlevi de yerine getiren doğal bir zenginliktir (Dugan 1990; Katip vd. 2015; Aksoy vd. 2016). Ancak hızlı nüfus artışı, yanlış alan kullanımları, sanayileşme, kentsel büyümeler gibi daha birçok unsurun sonucu olarak pek çok sulak alan doğal olarak yok olma ya da doğal özelliğini ve işlevini kaybetme tehlikesiyle karşı karşıya kalmıştır (Aydın ve Güngör 2015). Sulak alanların korunması ve geliştirilmesi ile ilgili gerekli önlemler ve tedbirler alınmadığı sürece, telafisi mümkün olmayan bozulmalara hatta yok olmaya doğru gidecektir (Demir vd. 2011). Sulak alanlarda kirlenmeye neden olan kaynaklar, noktasal kaynaklar ve yayılı (noktasal olmayan) kaynaklar olmak üzere ikiye ayrılır (Turan ve Ülkü 2013). 
Noktasal kaynaklar; evsel ve endüstriyel atık su deşarjları, tehlikeli atık dökülmeleri, yer altı depolama tankları, kimyasal stokları, maden atık havuzları, fosseptiklerden kaynaklanan sızıntılardan oluşmaktadır. Noktasal olmayan kaynak olarak isimlendirilen yayılı kaynaklardan meydana gelen kirlilik tarımsal aktivitelerden (sulama, drenaj, yüzeysel akış, erozyon, pestisit uygulamaları ve gübreleme), yerleşim alanlarında oluşan yüzeysel akıştan, inşaat, madencilik ve ormancılık faaliyetlerinden, parklar, çayırlar ve golf sahalarına uygulanan pestisit ve gübrelerden, yollara uygulanan tuzlama çalışmalarından, atmosferik çökelmelerden, hayvancılık faaliyetlerinden kaynaklanmaktadır (Loague ve Corwin 2005; Dowd vd. 2008; He vd. 2011; Katip vd. 2013).

Ramsar Sözleşmesi kapsamına alınan ve Türkiye’nin önemli bir sulak alanı olan Uluabat Gölü, nüfusun, ekonominin ve endüstrinin hızlı geliştiği bir havza içerisinde yer almaktadır (Salihoğlu ve Karaer 2004). Bu nedenle de Uluabat Gölü uzun yıllardan beri evsel ve endüstriyel sularla ve yağmur sularının neden olduğu yüzeysel akışlar ile kirletilmektedir (Hacısalihoğlu 2016).

$\mathrm{Bu}$ çalışmada ülkemiz için önemli bir sulak alan olan Uluabat Gölü üzerinde gerçekleştirilen araştırma sonuçları sunulmuştur. Uluabat Gölü havzasında bulunan noktasal kirletici kaynaklara ait debi değerleri ve kirlilik yükleri, Ağustos 2013-Temmuz 2014 dönemlerini kapsayan süreçte izlenmiştir. Göle ulaşan kirlilik yüklerinin mevsimsel ve y1llık değişimleri hesaplanmıştır. Kirleticilerin Uluabat Gölü su kalitesine olan etkileri değerlendirilmiş, alınabilecek tedbirler belirtilmiştir.

\section{Materyal ve Yöntem}

\section{1. Çalışma Alanı}

Uluabat Gölü, Marmara Bölgesi’nde (Bursa) yer alan, büyük ve sığ bir tatlı su gölüdür (Benzer ve Benzer 2018). Göl ortalama $2.5 \mathrm{~m}$ derinliğe sahiptir. Göldeki su derinliği yaz ile kış mevsimleri arasında ve yıllar bazında önemli miktarlarda değişiklik gösterebilmektedir. Su seviyesi genellikle kış mevsiminde yüksek, yaz mevsiminde ise su girdisinin az oluşu, buharlaşma ve gölden yapılan tarımsal amaçlı su çekimlerinin etkisiyle düşüktür (Hacısalihoğlu ve Karaer 2018). Gölün yüzey alanı, maksimum su seviyesinde $161 \mathrm{~km}^{2}$, minimum su seviyesinde $138 \mathrm{~km}^{2}$ olarak belirlenmiştir (Aksoy vd. 2016).

Gölü besleyen ve drene eden başlıca akarsular sırasıyla Mustafakemalpaşa (MKP) Çayı ve Kocasu Çayı (KÇ)'dır. Göl etrafında tarımsal sulamadan dönen drenaj sularının toplanıp göle iletilmesini sağlayan üç farklı noktasal kaynak (pompa istasyonu) bulunmaktadır. Bunlar; Atabay (API), Uluabat (UPİ) ve Karaoğlan (KPİ) pompa istasyonlarıdır. Ayrıca gölün doğusunda Akçalar Köyü’nde bulunan, evsel ve endüstriyel atık suların deşarj edildiği Akçalar Deresi (AD)'de debisi oldukça düşük olmasına rağmen önemli miktarda kirlilik taşıyan noktasal bir kaynaktır. Göle ait çalışma alanı, giriş ve çıkış akarsuları ile noktasal kaynaklar Şekil 1'de gösterilmiştir. Bu noktasal kaynakların konum bilgileri ise Tablo 1'de sunulmuştur.

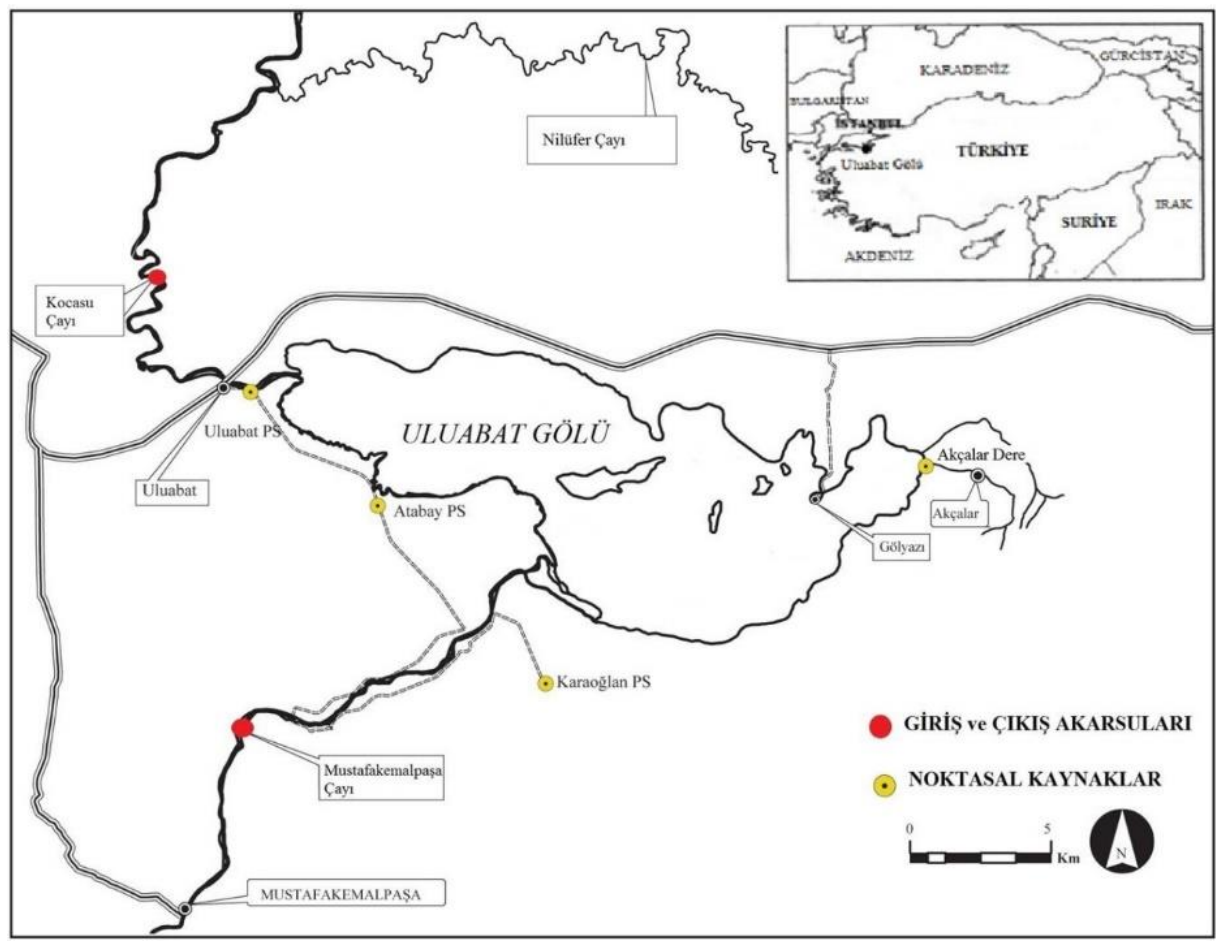

Şekil 1: Uluabat gölü, giriş (MKP Çayı) - çıkış (Kocasu Çayı) akarsuları ve noktasal kirlilik kaynakları 
Tablo 1: Noktasal Kaynaklar Konum Bilgileri

\begin{tabular}{|l|c|c|}
\hline İstasyon no & Enlem & Boylam \\
\hline Akçalar Deresi & $40^{\circ} 10^{\prime} 38^{\prime \prime}$ & $28^{\circ} 43^{\prime} 26^{\prime \prime}$ \\
\hline Atabay Pompa İstasyonu & $40^{\circ} 10^{\prime} 03^{\prime \prime}$ & $28^{\circ} 29^{\prime} 34^{\prime \prime}$ \\
\hline Karaoğlan Pompa İstasyonu & $40^{\circ} 06^{\prime} 37^{\prime \prime}$ & $28^{\circ} 33^{\prime} 45^{\prime \prime}$ \\
\hline Uluabat Pompa İstasyonu & $40^{\circ} 12^{\prime} 16^{\prime \prime}$ & $28^{\circ} 26^{\prime} 38^{\prime \prime}$ \\
\hline
\end{tabular}

\subsection{Analiz Çalışmaları}

Çalışma kapsamında daha önce de bahsedildiği üzere toplam dört farklı noktadan su numuneleri alınmıştır. Örnekleme programı belirlenirken, örnek alınacak nokta ve sayısı, laboratuvar olanakları, daha önce yapılmış çalışmalar, laboratuvar ile arazi arasındaki mesafe, proje bütçesi gibi temel faktörler baz alınmıştır. İzleme sürecinde su numuneleri, Ağustos 2013 ile Temmuz 2014 tarihleri arasındaki süreçte tüm mevsimleri kapsayacak şekilde, her ay düzenli olarak alınmıştır. Su numuneleri alınırken, Hydro-Bios marka standart su numune alma aparatı kullanılmıştır. Alınan numuneler, $\mathrm{HNO}_{3}$ ve deiyonize su ile yıkanmış koyu renkli polietilen (PE) şişelere aktarılarak, soğutucular

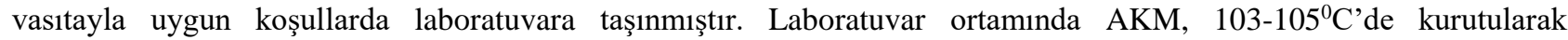
gravimetrik yöntemle, $\mathrm{BOI}_{5}$ ve KOI parametreleri standart metotlara göre (APHA 1998), $\mathrm{NH}_{4}-\mathrm{N}, \mathrm{NO}_{3}-\mathrm{N}, \mathrm{TN}$ su buharı destilasyonu yöntemiyle (Bremner ve Mulvaney 1982), PO $_{4}-\mathrm{P}$ ve TP askorbik asit yöntemiyle (APHA 1998) ölçülmüştür. Analizler iki tekrarlı olacak şekilde gerçekleştirilmiş ve ortalamaları alınmıştır.

Kirletici yüklerinin hesaplanabilmesi için örnekleme noktalarında debi ölçümü yapılması gerekmektedir. Bu amaçla, her ay su numunelerinin alınması sırasında Kocasu Çayı ve Akçalar Deresi’nde debi ölçüm işlemi gerçekleştirilmiştir. AOTT marka muline ile her ay örneklemeye gidildiğinde doğrudan ölçüm yapılarak düzenli olarak ölçülmüştür. Diğer örnekleme noktalarımıza ait debi değişimleri Devlet Su İşleri 1. Bölge Müdürlüğü tarafından düzenli olarak ölçülmektedir. Dolayısıyla bu noktaların aylık ortalama debi değerleri bu kurumdan veri temin edilerek belirlenmiştir. Kirletici yükü, kirletici konsantrasyonu ve debinin bir fonksiyonudur. Buna göre kirletici yükleri;

$W=Q \times C$

formülasyonu gereğince hesaplanmıştır. Burada; $W$ : kirlilik yükü (ton/yıl), $Q$ : debi (m³/s), C: kirletici konsantrasyonu (mg/l)'nu ifade etmektedir (Chapra 1996).

\section{Bulgular ve Tartışma}

Göllerde su kalitesinin değerlendirilebilmesi için havzasındaki su kullanım alanlarının, su seviyesinin, uzun dönem yağış ve debi ortalamalarının belirlenmesi oldukça önemlidir. Çalışma alanına ait örneklem noktalarının aylık debi değişimleri Tablo 2'de verilmiştir.

Tablo 2: Uluabat Gölü giriş (MKP Çayı) ve Çıkış (Kocasu Çayı) akarsuları ile noktasal kaynaklara ait aylık ortalama debi değerleri

\begin{tabular}{|l|l|l|l|l|l|l|l|l|l|l|l|l|}
\hline Debi $\left(\mathrm{m}^{3} / \mathrm{sn}\right)$ & $\begin{array}{l}\text { Ağu. } \\
2013\end{array}$ & Eyl. & Ekim & Kas. & Ara. & $\begin{array}{l}\text { Ocak } \\
2014\end{array}$ & Şub. & Mart & Nis. & May. & Haz. & $\begin{array}{l}\text { Tem. } \\
2014\end{array}$ \\
\hline MKP Çay1 & 9.83 & 9.92 & 11.1 & 6.94 & 5.92 & 7.00 & 7.16 & 11.5 & 6.59 & 18.30 & 12.7 & 12.6 \\
\hline Kocasu Çay1 & 12.6 & 12.9 & 14.0 & 13.92 & 25.0 & 18.3 & 18.7 & 20.15 & 19.2 & 36.8 & 28.4 & 16.7 \\
\hline AD & 0.01 & 0.01 & 0.004 & 0.005 & 0.006 & 0.02 & 0.01 & 0.01 & 0.08 & 0.13 & 0.11 & 0.005 \\
\hline APİ & 0.97 & 0.67 & 0.25 & 0.16 & 0.39 & 0.34 & 0.22 & 0.20 & 0.18 & 0.40 & 0.59 & 0.64 \\
\hline KPİ & 0.17 & 0.18 & 0.16 & 0.13 & 0.16 & 0.17 & 0.15 & 0.15 & 0.14 & 0.22 & 0.19 & 0.05 \\
\hline UPİ & 0.80 & 0.88 & 0.42 & 0.06 & 0.10 & 0.12 & 0.16 & 0.16 & 0.13 & 0.54 & 0.94 & 0.80 \\
\hline
\end{tabular}

AD: Akçalar Dere, API: Atabay Pompa İstasyonu, KPI: Karaoğlan Pompa İstasyonu, UPI: Uluabat Pompa İstasyonu

Tablo 2 incelendiğinde MKP Çayı ve Kocasu Çayı debilerinin (göl giriş ve çıkış akarsuları) diğer noktasal kaynaklara göre oldukça fazla miktarda debiye sahip olduğu görülmektedir. Akçalar Deresi ise en düşük debiye sahip noktasal kaynaktır. MKP ve Kocasu Çayları ile noktasal kaynaklara ait debi değerli görselleştirilmiş ve Şekil 2’de sunulmuştur.

Göle giren noktasal kirletici kaynakların aylık debi değerlerinin ortalamaları alınarak belirlenen yıllık ortalamalara göre en yüksek ve en düşük değerler MKP Çayı ve Akçalar Deresi'nde 9.96 ve $0.03 \mathrm{~m}^{3} / \mathrm{sn}$ olarak belirlenmiştir. Kirletici kaynakların yıllık debi ortalamalarının büyüklük sıralamaları ise MKP $>$ KÇ $>$ UPI $>$ APİ $>$ KPI $>$ AD şeklindedir. 

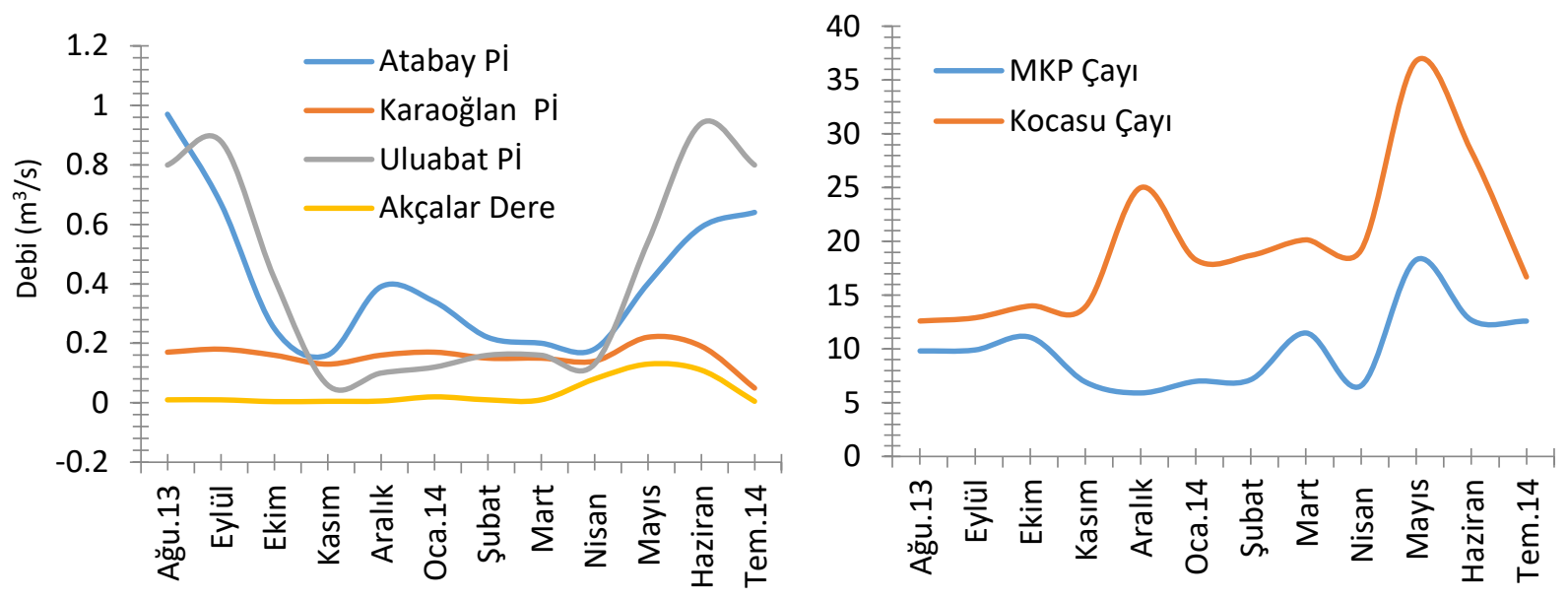

Şekil 2: Uluabat Gölü giriş (MKP Çayı) ve çıkış (Kocasu Çayı) akarsuları ile noktasal kaynaklara ait aylık ortalama debi değerleri değişimi

Göl havzasında bulunan çok sayıda yerleşim yerleri, endüstriler, kömür ve maden tesisleri, çevreyi önemsemeden bilinçsizce sürdürülen tarımsal faaliyetler, gölde kirliliğin daha da artmasına, sahip olduğu tür çeşitliliğinin azalmasına neden olmaktadır. Göl havzasında gerçekleştirilen pek çok çalışma gölde su kirliliği, sediment birikimi, ötrofikasyon, tür azalışı ve ağır metal kirliliğinin devam ettiğini doğrulamaktadır (Benzer ve Benzer 2018; Hacısalihoğlu vd. 2016; Katip vd. 2015; İleri vd. 2014, Sarmaş1k vd. 2011; Kazanc1 vd. 2010; Katip 2010; Dalkıran vd. 2006). Uluabat Gölü havzası ve civarındaki arazilerden kaynaklanan sediment taşınımı ve kirlenme problemleri gölde su ve sediment kalitesinin bozulmasına, kirlenmesine veya tamamen yok olmasına neden olacak tehditler oluşturmaktadır. Doğal arazi yapısından kaynaklanan kirlenmenin yanı sıra insan faaliyetlerinin olumsuz etkileri sonucu da Uluabat Gölü zarar görmektedir (Barlas vd. 2005; Aksoy vd. 2016). Havzanın jeolojik ve jeomorfolojik yapısı, iklim ve bitki örtüsü, arazinin dik eğime sahip olması gibi etkilerin yanı sıra antropojenik faktörlerinde eklenmesiyle havzada su erozyonu oluşmakta ve bu durum göldeki kirlilik yükünü artırarak, su kalitesini olumsuz yönde etkilemektedir (Aksoy vd. 2016).

Mustafakemalpaşa Çayı göle oldukça yüksek miktarda kirletici boşaltmaktadır. Gölde su seviyesi ve akarsu debileri özellikle yağışların bol olduğu dönemlerde artış göstermektedir. Dolayısıyla kirletici yük miktarı da, debi ile orantılı olarak artmaktadır. Ancak bu durum kirletici konsantrasyonlarının arttığı anlamında düşünülmemelidir, debi artışı nedeni ile olabileceği de düşünülebilir. Uluabat Gölü giriş ve çıkış akarsuları su kalitesi parametreleri analiz sonuçları ile Yüzeysel Su Kalitesi Yönetimi Yönetmeliği Su Kalite Sınıfları Tablo 3’de verilmiştir.

Tablo 3: Uluabat Gölü giriş (MKP Çayı) ve çıkış (Kocasu Çayı) akarsuları su kalitesi parametreleri istatistiksel değerleri ve yüzeysel su kalitesi yönetmeliği sınır değerleri

\begin{tabular}{|c|c|c|c|c|c|c|c|c|}
\hline İstasyon & \multicolumn{2}{|c|}{ MKP } & \multicolumn{2}{|c|}{ KÇ } & \multicolumn{4}{|c|}{ (YSKYY) Su Kalite Sınıfları } \\
\hline Konsantrasyon & Ort \pm SD & Max-Min & Ort \pm SD & $\begin{array}{l}\text { Max- } \\
\text { Min }\end{array}$ & $\begin{array}{c}\text { I } \\
\text { (Yüksek } \\
\text { Kaliteli Su) }\end{array}$ & $\begin{array}{c}\text { II } \\
(\mathrm{Az} \text { Kirli } \\
\mathrm{Su})\end{array}$ & $\begin{array}{c}\text { III } \\
(\text { Kirli } \\
\mathrm{Su})\end{array}$ & $\begin{array}{c}\text { IV } \\
(\text { Çok Kirli } \\
\mathrm{Su})\end{array}$ \\
\hline $\mathrm{AKM}(\mathrm{mg} / \mathrm{l})$ & $32.3 \pm 17.6$ & $60-8$ & $13.6 \pm 14.8$ & $60-8$ & & & & \\
\hline $\mathrm{NH}_{4}-\mathrm{N}(\mathrm{mg} / \mathrm{l})$ & $1.1 \pm 1.4$ & $4.2-0$ & $0.7 \pm 1.0$ & $3.5-0$ & & & & \\
\hline $\mathrm{NO}_{3}-\mathrm{N}(\mathrm{mg} / \mathrm{l})$ & $1.1 \pm 1.9$ & $6.3-0$ & $0.93 \pm 1.67$ & $4.9-0$ & & & & \\
\hline $\mathrm{TN}(\mathrm{mg} / \mathrm{l})$ & $16.8 \pm 6.9$ & $26.6-10.5$ & $14.1 \pm 5.4$ & $22.4-7.7$ & & & & \\
\hline $\mathrm{PO}_{4}-\mathrm{P}(\mu \mathrm{g} / \mathrm{l})$ & $61.5 \pm 10.9$ & $73.3-40.8$ & $50.4 \pm 9.7$ & $63-33$ & & & & \\
\hline $\mathrm{TP}(\mu \mathrm{g} / \mathrm{l})$ & $81.8 \pm 12.9$ & $102.3-60.9$ & $75.4 \pm 11.5$ & $96.6-63$ & $<30$ & $30-160$ & $160-650$ & $>650$ \\
\hline $\mathrm{KOI}(\mathrm{mg} / \mathrm{l})$ & $90.3 \pm 73.5$ & $256-32$ & $80.6 \pm 43.7$ & $160-32$ & $<25$ & $25-50$ & $50-70$ & $>70$ \\
\hline $\mathrm{BOI}_{5}(\mathrm{mg} / \mathrm{l})$ & $31.7 \pm 10.8$ & $50-20$ & $29.3 \pm 8.6$ & $38-18$ & $<4$ & $4-8$ & $8-20$ & $>20$ \\
\hline
\end{tabular}

Ort: Ortalama, SD: Standart Sapma, Max: Maksimum Değer, Min: Minimum Değer

Tablo 3 incelendiğinde, göle giriş yapan MKP Çayı'nın ortalama AKM konsantrasyonunun 32.3 mg/l, NH4-N ve $\mathrm{NO}_{3}-\mathrm{N}$ konsantrasyonlarının $1.1 \mathrm{mg} / \mathrm{l}$, TN konsantrasyonunun $16.8 \mathrm{mg} / \mathrm{l}, \mathrm{PO}_{4}-\mathrm{P}$ konsantrasyonunun $61.5 \mu \mathrm{g} / \mathrm{l}, \mathrm{TP}$ konsantrasyonunun $81.8 \mu \mathrm{g} / \mathrm{l}$, KOI konsantrasyonunun $90.3 \mathrm{mg} / \mathrm{l}$ ve $\mathrm{BOI}_{5}$ konsantrasyonunun ise $31.7 \mathrm{mg} / \mathrm{l} \mathrm{olduğu}$ tespit edilmiştir. 
Gölü drene eden Kocasu Çayı'nda ölçülen kirletici parametrelerin ortalama konsantrasyon değerleri ise AKM 13.6 $\mathrm{mg} / \mathrm{l}, \mathrm{NH}_{4}-\mathrm{N} 0.7 \mathrm{mg} / \mathrm{l}, \mathrm{NO}_{3}-\mathrm{N} 0.93 \mathrm{mg} / \mathrm{l}, \mathrm{TN} 14.1 \mathrm{mg} / \mathrm{l}, \mathrm{PO}_{4}-\mathrm{P} 50.4 \mu \mathrm{g} / \mathrm{l}$, TP $75.4 \mu \mathrm{g} / \mathrm{l}, \mathrm{KOI} 80.6 \mathrm{mg} / \mathrm{l} \mathrm{ve}$ BOI 29.3 mg/l olarak ölçülmüştür. Bu durum, MKP Çayı'nın Kocasu Çayı'na göre göle daha fazla konsantrasyonda kirlilik taşıdığını göstermektedir.

Yüzeysel su kütlelerinde maruz kalınan baskılar ve etkilerinin değerlendirilebilmesi için, Yüzeysel Su Kalitesi Yönetimi Yönetmeliği (YSKYY) EK 1'e göre mutlaka noktasal baskıların belirlenmesi gerekir. Bu nedenle Tablo 3'de verilen, giriş ve çıkış akarsularında ölçülen konsantrasyon değerleri, Yüzeysel Su Kalitesi Yönetimi Yönetmeliği (YSKYY) Ek 5 "Kıtaiçi Yüzeysel Su Kaynaklarının Sınıflarına Göre Kalite Kriterleri” ile karşılaştırılmıştır. Ölçümü gerçekleştirilen parametrelerden KOI, $\mathrm{BOI}_{5}$ ve TP için yönetmelik değerleri mevcut olup, değerlendirme bu parametreler üzerine yapılmıştır. MKP Çayı'nda ölçülen ortalama TP konsantrasyonu (81.8 $\mu \mathrm{g} / \mathrm{l})$ yönetmelik değerleri

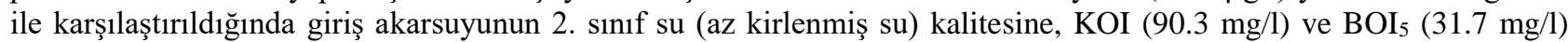
konsantrasyonları açısından değerlendirildiğinde ise 4. sınıf su (çok kirlenmiş su) kalitesine sahip olduğu görülmektedir. Benzer şekilde Kocasu Çayı kirletici konsantrasyonları yönetmelik değerleri ile karşılaştırıldığında, TP (75.4 $\mu \mathrm{g} / \mathrm{l})$ açısından 2. sınıf su (az kirlenmiş su) kalitesine, KOI $(80.6 \mathrm{mg} / \mathrm{l})$ ve BOI $(29.3 \mathrm{mg} / \mathrm{l})$ parametreleri açısından ise 4 . sınıf su (çok kirlenmiş su) kalitesine sahip olduğu tespit edilmiştir.

Uluabat Gölü noktasal kirletici kaynaklara ait su kalitesi izleme sonuçları istatistiksel değerleri Tablo 4'de verilmiştir.

Tablo 4: Noktasal kirletici kaynaklar su kalitesi parametreleri istatistiksel değerleri

\begin{tabular}{|c|c|c|c|c|c|c|c|c|}
\hline İstasyon & \multicolumn{2}{|l|}{ AD } & \multicolumn{2}{|c|}{ API } & \multicolumn{2}{|c|}{ KPI } & \multicolumn{2}{|c|}{ UPI } \\
\hline Konsantrasyon & Ort \pm SD & Max-Min & Ort \pm SD & Max-Min & Ort \pm SD & Max-Min & Ort \pm SD & $\begin{array}{l}\text { Max- } \\
\text { Min }\end{array}$ \\
\hline $\mathrm{AKM}(\mathrm{mg} / \mathrm{l})$ & $32 \pm 18.8$ & $76-12$ & $23 \pm 19.3$ & $64-4$ & $11 \pm 5.1$ & $24-4$ & $32.3 \pm 21.7$ & $80-12$ \\
\hline $\mathrm{NH}_{4}-\mathrm{N}(\mathrm{mg} / \mathrm{l})$ & $0.9 \pm 1.2$ & $4.2-0$ & $1.5 \pm 1.4$ & $5.6-0$ & $0.2 \pm 0.5$ & $1.4-0$ & $1.9 \pm 3.0$ & $10.5-0$ \\
\hline $\mathrm{NO}_{3}-\mathrm{N}(\mathrm{mg} / \mathrm{l})$ & $1.1 \pm 1.5$ & $3.5-0$ & $1.8 \pm 1.3$ & $3.5-0$ & $1.2 \pm 1.5$ & $3.5-0$ & $2.5 \pm 2.0$ & $6.3-0$ \\
\hline $\mathrm{TN}(\mathrm{mg} / \mathrm{l})$ & $22.8 \pm 11.7$ & $51.1-11.9$ & $28.9 \pm 10.1$ & $42-8.4$ & $19.9 \pm 15.1$ & $49.7-6.3$ & $26.3 \pm 7.6$ & $35-13.3$ \\
\hline $\mathrm{PO}_{4}-\mathrm{P}(\mu \mathrm{g} / 1)$ & $174.3 \pm 98.3$ & $\begin{array}{l}366.5- \\
78.5\end{array}$ & $191.8 \pm 100.5$ & $\begin{array}{l}10.4- \\
55.2\end{array}$ & $56.9 \pm 10.8$ & $85.2-47.5$ & $277.8 \pm 147.7$ & $\begin{array}{l}477.6- \\
31.9\end{array}$ \\
\hline $\mathrm{TP}(\mu \mathrm{g} / \mathrm{l})$ & $234 \pm 137.6$ & $\begin{array}{l}499.3- \\
99.2\end{array}$ & $368.2 \pm 200.6$ & $\begin{array}{l}557.8- \\
67.6\end{array}$ & $240.1 \pm 210.8$ & $\begin{array}{l}533.5- \\
58.3\end{array}$ & $415.4 \pm 220.8$ & $\begin{array}{l}616.2- \\
47.3\end{array}$ \\
\hline $\mathrm{KOI}(\mathrm{mg} / \mathrm{l})$ & $93.3 \pm 45.6$ & $192-48$ & $90.6 \pm 24.9$ & $128-48$ & $65.3 \pm 18.6$ & $96-48$ & $108.0 \pm 35.5$ & $160-48$ \\
\hline $\mathrm{BOI}_{5}(\mathrm{mg} / \mathrm{l})$ & $38.6 \pm 13.7$ & $63-20$ & $45.2 \pm 12.5$ & $75-25$ & $27 \pm 7.5$ & $38-13$ & $48.2 \pm 19.7$ & $85-23$ \\
\hline
\end{tabular}

Ort: Ortalama, SD: Standart Sapma, Max: Maksimum Dĕ̌er, Min: Minimum Değer

Tablo 4 değerlendirildiğinde, Uluabat pompa istasyonunun ortalama en yüksek AKM konsantrasyonuna (32.3 mg/l) sahip olduğu görülmektedir. İstatistiksel değerler incelendiğinde yine Uluabat pompa istasyonunda maksimum (80 $\mathrm{mg} / \mathrm{l})$, Karaoğlan ve Atabay pompa istasyonlarında ise minimum (4 mg/l) AKM konsantrasyonları ölçülmüştür. Ayrıca, Akçalar Deresi'nin de dönemsel olarak oldukça yüksek miktarlarda (76 mg/l) AKM taşıdığı söylenebilir. $\mathrm{NH}_{4}-\mathrm{N}$ konsantrasyonları incelendiğinde, Uluabat pompa istasyonunun en yüksek amonyum azotu konsantrasyonuna (1.9 mg/l) sahip olduğu görülmektedir. İzleme sürecinde ölçülen en yüksek $\mathrm{NH}_{4}-\mathrm{N}$ konsantrasyonu yine Uluabat pompa istasyonunda $(10.5 \mathrm{mg} / \mathrm{l})$ ölçülmüştür. En düşük $\mathrm{NH}_{4}-\mathrm{N}$ konsantrasyonu ise tüm örnekleme noktalarında $(0 \mathrm{mg} / \mathrm{l})$ gözlenmiştir. $\mathrm{NO}_{3}-\mathrm{N}$ değerleri incelendiğinde, en yüksek ortalama nitrat azotu konsantrasyonu Uluabat pompa istasyonunda $(2.5 \mathrm{mg} / \mathrm{l})$ ölçülmüştür. İstatistiksel değerlendirmeye göre ise izleme süresince en yüksek değer yine Uluabat pompa istasyonunda $(6.3 \mathrm{mg} / \mathrm{l})$, en düşük değer ise tüm örnekleme noktalarında $(0 \mathrm{mg} / \mathrm{l})$ olarak ölçülmüştür. TN değerleri incelendiğinde, en yüksek ortalama toplam azot konsantrasyonu Atabay pompa istasyonunda (28.9 mg/l) ölçülmüş̧ür. İstatistiksel değerlendirmeye göre ise izleme süresince en yüksek toplam azot konsantrasyonu Akçalar Deresi'nde $(51.1 \mathrm{mg} / \mathrm{l})$, en düşük değer ise Karaoğlan pompa istasyonunda $(6.3 \mathrm{mg} / \mathrm{l})$ ölçülmüştür. $\mathrm{PO}_{4}-\mathrm{P}$ ölçüm sonuçlarına göre ise en yüksek fosfat konsantrasyonu Uluabat pompa istasyonunda (277.8 $\mu \mathrm{g} / \mathrm{l})$, en düşük fosfat konsantrasyonu ise Karaoğlan pompa istasyonunda $(56.9 \mu \mathrm{g} / \mathrm{l})$ gözlenmiştir. Fosfat konsantrasyonlarına ait istatistiksel değerler incelendiğinde maksimum ve minimum değerler yine Uluabat pompa istasyonunda (mak 477.6 $\mu \mathrm{g} / \mathrm{l}$; min 31.9 $\mu \mathrm{g} / \mathrm{l})$ ölçülmüştür. TP değerlerine bakıldığında fosfata benzer şekilde maksimum ve minimum değerler yine Uluabat pompa istasyonunda (mak $616.2 \mu \mathrm{g} / \mathrm{l}$; min $47.3 \mu \mathrm{g} / \mathrm{l}$ )ölçülmüştür. KOI parametresi istatistik değerleri incelendiğinde en yüksek konsantrasyon Akçalar Deresi'nde (192 mg/l) ve en düşük konsantrasyon tüm örnekleme noktalarda $48 \mathrm{mg} / 1$ olarak ölçülmüştür. En yüksek BOI $_{5}$ değeri Uluabat pompa istasyonunda $(85 \mathrm{mg} / \mathrm{l})$, en düşük değer ise Karaoğlan pompa istasyonunda $(13 \mathrm{mg} / \mathrm{l})$ gözlenmiştir. 
Biyolojik ve kimyasal oksijen ihtiyacı (BOI ve KOI) parametreleri, su kaynaklarında kirlilik derecesinin belirlenmesinde kullanılan önemli iki parametredir. BOI parametresi, bakterilerin organik maddeleri kararlı hale getirmeleri için gerekli olan oksijen miktarını ifade eder, su kaynaklarında organik kirlilik yük mevcudiyetinin önemli bir göstergesidir (Şengül ve Müezzinoğlu 2001). KOI parametresi ise organik maddelerin redoks reaksiyonlarıyla kararlı hale getirilmesi esasına dayanır, bu işlemde yüksek sıcaklıkta potasyum dikromat kullanılmaktadır (Elmacı vd. 2010; Turan ve Ülkü 2013). Genel olarak Karaoğlan pompa istasyonunun diğer tüm noktasal kaynaklara göre kirletici konsantrasyonunun daha düşük olduğu gözlenmiştir. Noktasal kaynaklara ait kirleticilerin ortalama konsantrasyonları YSKYY Ek5'e göre değerlendirildiğinde TP konsantrasyonu (AD: 234; APİ: 368.2; KPİ: 240.1; UPİ: $415.4 \mu \mathrm{g} / \mathrm{l}$ ) açısından tüm noktasal kaynakların III. sınıf su (kirli su) kalitesine sahip oldukları tespit edilmiştir. BOI 5 parametresi açısından (AD: 38.6; APİ: 45.2; KPİ: 27; UPİ: $48.2 \mathrm{mg} / \mathrm{l}$ ) yine tüm noktasal kaynakların IV. sınıf su (çok kirli su) kalitesine sahip oldukları gözlenmiştir. KOI parametresi (AD: 93.3; APİ: 90.6; UPİ: 108 mg/l) açısından değerlendirildiğinde ise KPİ hariç diğer tüm noktasal kaynakların IV. sınıf su (çok kirli su) kalitesine sahip oldukları tespit edilmiştir. KPİ ise ortalama $65.3 \mathrm{mg} / \mathrm{l}$ KOI konsantrasyonuna sahip olup, bu değer yönetmelik ile karşılaştırıldığında III. sınıf su kalitesine sahip olduğu görülmektedir. Ancak genel bir değerlendirme yapılacak olursa, parametrelerden herhangi birinin IV. sınıf su kalitesine sahip olması halinde, o su kaynağının niteliği değişmez, yani IV. sinıf su kalitesine sahiptir.

Çalışma da belirlenen noktasal kaynaklara ait debi değerleri ve ölçülen kirletici konsantrasyon değerleri çarpılarak toplam kirlilik yükleri (ton/yıl biriminde) hesaplanmış ve Tablo 5'de sunulmuştur.

Tablo 5: Kirletici kaynaklara ait yıllık toplam kirlilik yükleri

\begin{tabular}{|c|c|c|c|c|}
\hline İstasyon & AD & APİ & KPİ & UPİ \\
\hline TN (ton/y1l) & 19.6 & 382.4 & 103.8 & 333.6 \\
\hline $\mathrm{NH}_{4}-\mathrm{N}($ ton/y1l) & 0.8 & 18.9 & 2.4 & 9.4 \\
\hline $\mathrm{NO}_{3}-\mathrm{N}($ ton/y1l) & 0.7 & 29.9 & 6.0 & 43.3 \\
\hline TP (ton/y1l) & 0.3 & 4.5 & 1.2 & 5.3 \\
\hline $\mathrm{PO}_{4}-\mathrm{P}$ (ton/y1l) & 0.2 & 2.2 & 0.3 & 3.0 \\
\hline KOI (ton/y1l) & 74.0 & 968.8 & 553.5 & 1570.0 \\
\hline $\mathrm{BOI}_{5}($ ton$/ \mathrm{y} 1)$ & 50.5 & 642.6 & 136.6 & 662.5 \\
\hline AKM (ton/y1l) & 41.4 & 283.5 & 57.1 & 368.4 \\
\hline
\end{tabular}

Tablo 5 incelendiğinde, göle taşınan kirlilik yükleri büyüklük sıralaması UPİ > APİ > KPİ > AD şeklinde olduğu görülmektedir. Özellikle bu noktasal kaynaklardan, göle yüksek miktarlarda TN, KOI, BOI 5 ve AKM girişi söz konusudur. Göle ve havzasına ulaşan evsel ve endüstriyel atık sular (özellikle gıda sanayi), hayvancılık ve tarımsal faaliyetler, organik yük ve toplam azotun temel kaynaklarıdır (Katip 2010). Noktasal kaynaklardan göle ulaşan organik yük, azot ve fosforun yüksek azot ve fosfat içerikli gübreler kullanılmasından kaynaklandığı düşünülmektedir. Sucul ortamlarda azot ve fosfor verimlilik sınırlayıcı elementtirler. Katip vd. (2013) gerçekleştirdikleri çalışmalarında, Uluabat Gölü'ne ulaşan azot ve fosfor yüklerinin başka bir kaynağının da Akçalar Köyü’nde bulunan et kesimhanelerinden kaynaklandığını, burada oluşan atık suların Akçalar Deresi aracılığı ile Uluabat Gölü’ne ulaştığını tespit etmişlerdir. Akçalar Deresi'nden gelen kirlilik yüklerinin düşük olması, bu su kaynağının debisinin çok düşük olması ve dönemsel olarak deşarjlar yapılmasından kaynaklanmaktadır. Uluabat pompa istasyonunun kirlilik yükünün çok yüksek olması ise Mustafakemalpaşa ilçesine en yakın noktasal kaynak olmasından kaynaklanmaktadır. Bu ilçe yoğun tarım yapılan bir ilçe olup, özellikle ilkbahar ve yaz mevsimlerinde Türkiye'nin önemli domates üretim merkezlerinden birisidir (Yalçın vd. 2018). Noktasal kirletici kaynaklara ait su kalitesi parametrelerinin mevsimsel değişimleri Şekil 3'de grafiklerde gösterilmiştir. Şekil 3 incelendiğinde, en yüksek TN yükü ilkbahar mevsiminde Uluabat pompa istasyonunda (24.4 ton/yıl), en düşük TN yükü ise sonbahar mevsiminde Akçalar Deresi'nde (0.27 ton/yıl) gözlenmiştir. $\mathrm{NH}_{4}-\mathrm{N}$ yükü Karaoğlan pompa istasyonunda hiç gözlenmemiştir. Diğer istasyonlar içerisinde en yüksek $\mathrm{NH}_{4}-\mathrm{N}$ yükü yaz mevsiminde Uluabat pompa istasyonunda (3.75 ton/y1l), en düşük $\mathrm{NH}_{4}-\mathrm{N}$ yükü ise ilkbahar mevsiminde Atabay, Karaoğlan ve Uluabat pompa istasyonlarında ( 0 ton/yıl) gözlenmiştir. En yüksek $\mathrm{NO}_{3}-\mathrm{N}_{\text {yükü yaz }}$ mevsiminde Atabay pompa istasyonunda (6.7 ton/yıl), en düşük $\mathrm{NO}_{3}-\mathrm{N}$ yükü ise ilkbahar ve sonbahar mevsimlerinde Atabay pompa istasyonunda (0 ton/yıl) ölçülmüştür. Azot fraksiyonlarının özellikle yaz mevsiminde artış göstermesi, bu dönemde artan tarımsal faaliyetler ve kimyasal gübreleme kaynaklı olabileceğini düşündürmüştür. Katip vd. (2013) Uluabat Gölü Akçalar deresinde gerçekleştirdikleri su kalitesi izleme çalışmalarında TN (22.4 ton/yıl) ve $\mathrm{NO}_{3}-\mathrm{N}$ (3.04 ton/yıl) formlarının özellikle temmuz ayında en yüksek kirlilik yüklerine sahip olduklarını gözlemlemişlerdir. Yaz mevsiminde, sıcaklık ve buharlaşmanın artması kirletici konsantrasyonlarını da arttırmaktadır. Buna karşın, kış aylarında ve ilkbaharda yağan yağmurlar göl içindeki konsantrasyonlarda seyrelmeye neden olmaktadır (Zeybek ve Kalyoncu 2016; Singh vd. 2008). 
İleri vd. (1997) benzer şekilde bir çalışma ile Sapanca Gölü’ne ulaşan kirletici yüklerinin mevsimsel değişimlerini izlemiş ve yaz mevsiminde azot yüklerinin en yüksek değerlere (Kjeldahl N: 3.38 ve $\mathrm{NO}_{3}-\mathrm{N}: 1.76$ ton/yıl) ulaştıklarını tespit etmişlerdir. Şekil 3'de TP ve $\mathrm{PO}_{4}-\mathrm{P}$ yükleri değişiminin benzer eğilim gösterdikleri görülmekte olup, en yüksek TP yükü ilkbahar mevsiminde Uluabat pompa istasyonunda (1.64 ton/y1l), en düşük TP yükü ise sonbahar mevsiminde Karaoğlan pompa istasyonunda (0.004 ton/yıl) gözlenmiştir. $\mathrm{PO}_{4}-\mathrm{P}$ yükü değerlendirildiğinde, en yüksek değer Uluabat pompa istasyonunda (1.25 ton/yıl) ilkbahar mevsiminde, en düşük değer ise Karaoğlan pompa istasyonunda (0.0005 ton/yıl) sonbahar mevsiminde ölçülmüştür. Kurtoğlu vd. (2015) Uluabat Gölü’nde yüksek toplam fosfor konsantrasyonlarının, Mustafakemalpaşa ve Karacabey ilçelerinden taşınan hayvansal, tarımsal ve endüstriyel atıksulardan kaynaklandıklarını ve kış mevsiminde düşük ölçülen fosfor konsantrasyonlarının havzadaki akış koşulları ve yağmurun etkisi ile meydana gelen seyrelmelerden kaynaklandığını belirtmişlerdir. Benzer şekilde Chao Gölü’nde toplam azot ve toplam fosfor konsantrasyonlarının en yüksek Ağustos ayında (yaz mevsiminde) ölçüldüğü tespit edilmiştir (Xu vd. 2003). Katip vd. (2013) Uluabat Gölü Akçalar deresinde gerçekleştirdikleri su kalitesi izleme çalışmalarında TP (0.58 ton/yıl) ve $\mathrm{PO}_{4}-\mathrm{P}$ (0.46 ton/yıl) formlarının özellikle mart ayında en yüksek kirlilik yüklerine sahip olduklarını gözlemlemişlerdir. $\mathrm{Bu}$ durumun ilkbahar ve yaz aylarında tarım ürünlerinden yüksek miktar ve kalitede ürün alabilmek için azotlu ve fosforlu gübreler kullanılmasından kaynaklandığını belirtmişlerdir (Katip vd. 2013). KOI ve BOI yükleri incelendiğinde benzer eğilim gösterdikleri görülmektedir. Her iki parametre için de en yüksek değerler Uluabat pompa istasyonunda ilkbahar mevsiminde (KOI: 220.4 ton/y1l; BOI: 112.3 ton/y1l), en düşük değerler ise sonbahar mevsiminde Akçalar Deresi’nde (KOI: 1.7 ton/yıl; BOI: 1.3 ton/yıl) gözlenmiştir.

Özellikle ilkbahar mevsiminde ölçülen yüksek AKM yükleri, tarımsal faaliyetlerin artması ve yağışların artmasına bağlı debi artışı sebebi ile olabileceğini düşündürmüştür. Ayrıca ilkbahar mevsiminde mikrobiyal aktivitenin artması sebebiyle organik maddelerin bozunma hızları artmaktadır. Bu nedenle de çözünmüş oksijen seviyesi düşmekte, BOI ve KOI seviyeleri artmaktadır. Benzer şekilde Haraz Nehri Havzası'nda Pejman vd. (2009) gerçekleştirdikleri çalışmalarında, BOI ve KOI konsantrasyonlarının ilkbahar ve yaz mevsimlerinde yüksek, sonbahar ve kış mevsimlerinde ise düşük olduğunu, bu durumun ilkbahar mevsiminde artan tarımsal faaliyetlerden kaynaklandığını, sonbahar ve kış mevsimlerinde yağış ve rüzgâr şiddetinin artması sonucu seyrelmelerin meydana geldiğini, bu nedenle organik kirlilik yükünün azaldığını belirtmişlerdir. En yüksek AKM yükü ilkbahar mevsiminde Uluabat pompa istasyonunda (127.2 ton/yıl), en düşük AKM yükü ise sonbahar mevsiminde Akçalar Deresi'nde (0.3 ton/yıl) gözlenmiştir. Şekil 2 incelendiğinde Uluabat pompa istasyonuna ulaşan debi miktarının nisan, mayıs ve haziran aylarında yüksek bir pik yaptığı görülmektedir. Bu durumun o dönem artan yağışlar etkisi ile olacağı ve AKM yükünün artmasının bu sebepten kaynaklandığı düşünülmektedir. Akçalar deresi ise en düşük debiye sahip noktasal kaynaktır, debisinin düşük olması sebebi ile göle ulaştırdığı AKM yükü de düşük değerlerdedir. Aksoy ve Özsoy (2002) çalışmalarında, iklim koşulları, yüzeysel akış ve çevresel faktörlerin etkisi ile Uluabat Gölü’nde önemli miktarda AKM birikimi gerçekleştiğini belirtmişlerdir.

\section{Sonuçlar ve Öneriler}

Bu çalışmada, ülkemiz için önemli sığ göllerden biri olan Uluabat Gölü havzasında gerçekleştirilen izleme sonuçları sunulmuştur. Göl havzasında bulunan noktasal kirletici kaynaklara ait debi değerleri ve kirlilik yükleri incelenmiştir. 4 farklı noktasal kaynakta, Ağustos 2013-Temmuz 2014 dönemlerinde, her ay düzenli olarak, fizikokimyasal ve hidrolojik izleme yapılmış, ölçülen parametrelerin mekânsal ve zamansal değişimleri incelenmiştir. Yüzeysel Su Kalitesi Yönetimi Yönetmeliği (YSKYY) EK 1'e göre, yüzeysel su kütlelerinde bask1 ve etkilerin değerlendirilebilmesi için, o su kütlesinin maruz kaldığı noktasal baskıların mutlaka belirlenmesi gerekir. Bu çalışma ile Uluabat Gölü’nün havzasında bulunan noktasal kaynakların tespit edilmesi ve göle taşıdıkları kirlilik yüklerinin belirlenmesi hedeflenmiştir. Göle giriş yapan MKP Çayı ve gölü drene eden Kocasu Çayı debilerinin diğer noktasal kaynaklara göre oldukça fazla miktarda debiye sahip olduğu gözlenmiştir. Akçalar Deresi en düşük debiye sahip noktasal kaynaktır. MKP Çayı'nın oldukça yoğun kirliliğe sahip olduğu, göle yüksek miktarlarda kirlilik taşıdığı tespit edilmiştir. Noktasal kaynaklara ait kirletici konsantrasyonları incelendiğinde Akçalar Deresi'nin en düşük kirletici konsantrasyonlarına sahip olduğu, buna karşılık Atabay ve Uluabat pompa istasyonlarının ise en yüksek kirletici konsantrasyonlarına sahip oldukları gözlenmiştir. Bu durum her iki noktasal kaynağın özellikle Mustafakemalpaşa ilçesine yakınlığından kaynaklandığını düşündürmektedir. Noktasal kaynaklarda ölçülen kirletici konsantrasyonları YSKYY EK5, Kıta içi Yüzeysel Su Kaynaklarının Sınıflarına Göre Kalite Kriterleri ile karşılaştırıldığında tüm noktasal kaynakların 4. sınıf su (çok kirlenmiş su) kalitesine sahip olduğu gözlenmiştir (KOI>70 mg/l, BOI>20 mg/l).Ton/yıl bazında kirlilik yükleri değerlendirildiğinde Akçalar Deresi'nin mevsimsel ve en az kirletici taşıdığı, Uluabat pompa istasyonunun ise en yoğun kirlilik yüküne sahip olduğu tespit edilmiştir. Bu kaynaklardan göle yüksek miktarlarda azot, fosfor ve organik yük taşındığı belirlenmiştir. Noktasal kaynaklardan göle ulaşacak olan kirliliği azaltmak, kirlilik sonucu ortaya çıkacak negatif etkileri nispeten azaltacaktır. Dolayısıyla, bu kaynaklar tarımsal sulamadan dönen drenaj sularını ihtiva ettiği için, tarımsal uygulamalarda çiftçi eğitilmeli, biyolojik gübrelerin uygun miktarlarda kullanımı teşvik edilmelidir. Kullanımı tehlikeli ve yasak olan tarım ilaçları kullandırılmamalıdır. 

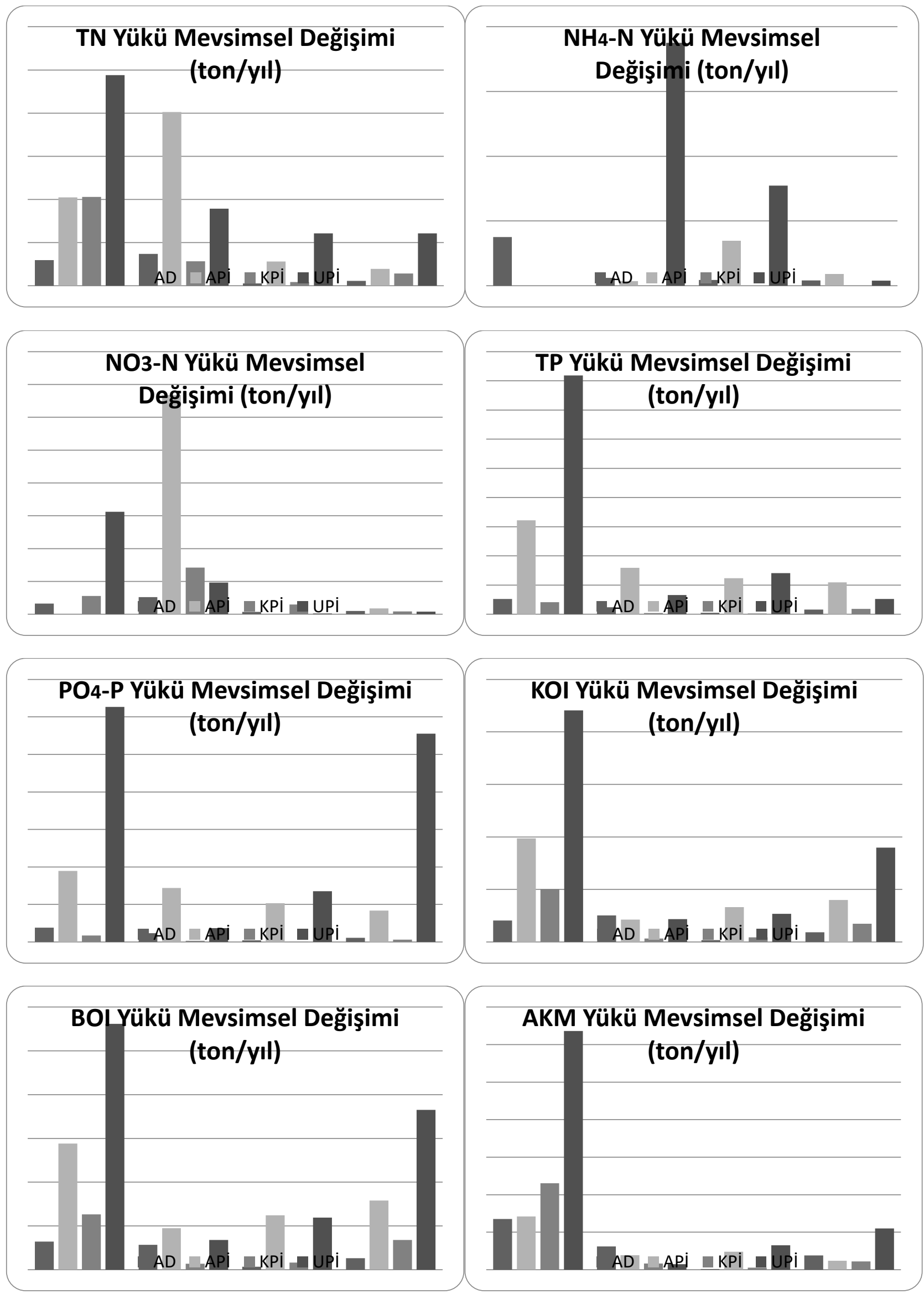

Şekil 3: Noktasal kirletici kaynakları ait kirlilik parametreleri mevsimsel değişimi 
Havzada oluşan atık suların mutlaka arıtıldıktan sonra deşarjı yapılmalıdır. Göl havzası bir bütün olarak değerlendirilmeli, sadece göl etrafındaki değil tüm havzadaki noktasal ve yayılı kaynaklar izlenmelidir, izleme çalışmaları süreklilik arz etmelidir. Göl havzasında modelleme çalışmaları ile olası senaryolar oluşturulmalı ve gerekli tedbirler önceden alınmalıdır.

\section{Teşekkür}

OUAP(M)-2013/6 nolu orta ölçekli bilimsel araştırma projemize destek vererek bu çalışmanın gerçekleştirilmesini sağlayan Uludağ Üniversitesi Bilimsel Araştırma Projeleri Komisyonu Başkanlığı’na teşekkür ederiz.

\section{Kaynaklar}

Aksoy E., Özsoy G., (2002), Investigation of multitemporal and use/cover and shoreline changes of the Uluabat Lake Ramsar site using RS and GIS, International Conference on Sustainable Land Use and Management, Çanakkale, Turkey, ss 73-79.

Aksoy E., Özsoy G., Karaata E.U., Karaer F., Katip A., Hacısalihoğlu S., Sarmaşık S., (2016), Ekosounder ve GIS teknikleri kullanılarak Uluabat Gölü'nde batimetrik haritalama, 6. Uzaktan Algılama-CBS sempozyumu (UZAL-CBS 2016), 5-7 Ekim, Adana, Türkiye, ss.348-356.

APHA, (1998), Standard methods for the examination of water and wastewater (20th ed.), American Public Health Association, Washington, D.C., USA.

Aydın M., Güngör Y., (2015), Effects of lake Uluabat and Gölyazı to human activities and tourism, Academic Journal of Science, $4(2), 89-100$

Barlas N., Akbulut N., Aydoğan M., (2005), Assessment of heavy metal residiues in the sediment and water samples of Uluabat Lake, Turkey, Bulletin of Environmental Contamination and Toxicology, 74, 286-293.

Benzer S., Benzer R., (2018), New perspectives for predicting growth properties of crayfish (Astacus leptodactylus Eschscholtz, 1823) in Uluabat Lake, Pakistan J. Zool., 50(1), 35-45.

Bremner J.M., Mulvaney C.S., (1982), Methods of soil analysis, American Society of Agronomy, USA, 159ss.

Chapra S.C., (1996), Surface Water-Quality Modeling, McGraw-Hill Series in Water Resources and Environmental Engineering, 784 ss.

Dalkıran N., Karacaoğlu D., Dere S., Sentürk E., Torunoğlu T., (2006), Factors affecting the current status of a eutrophic shallow lake (Lake Uluabat, Turkey): Relationships between water physical and chemical variables, Chemistry and Ecology, 22(4), 279298.

Demir M., Yıldız N.D., Irmak M.A., Yılmaz H., Yılmaz S., Özer S., (2011), Sulak alanların sürdürülebilirliği için ekosisteme bütüncül yaklaşım: Erzurum Örneği, II. Türkiye Sulak Alanlar Kongresi, 22-24 Haziran, Kırşehir, Türkiye.

Dowd B.M., Press D., Huertos M.L., (2008), Agricultural nonpoint source water pollution policy: The case of California's Central Coast. Agriculture, Ecosystems and Environment, 128, 151-161.

Dugan P.J., (1990), Wetland conservation: a review of current issues and required action, Gland, Switzerland, 96ss.

Elmacı A., Topaç F.O., Teksoy A., Özengin N., Başkaya H.S., (2010), Uluabat Gölü fizikokimyasal özelliklerinin yönetmelikler çerçevesinde değerlendirilmesi, Uludağ Üniversitesi Mühendislik-Mimarlık Fakültesi Dergisi, 15(1), 149-157.

Hacısalihoğlu S., (2016),Uluabat Gölü su kalitesinin modellenmesinde krom ve nikel metallerinin değerlendirilmesi, Doktora Tezi, Uludağ Üniversitesi, Fen Bilimleri Enstitüsü, Çevre Bilimleri Anabilim Dalı, Bursa.

Hacısalihoğlu S., Karaer F., (2018), Evaluation of water quality in eutrophic shallow lakes: case study on lake Uluabat, Turkey, International Journal of Agriculture, Environment and Food Sciences, 2(1), 18-28.

Hacısalihoğlu S., Karaer F., Katip A., (2016), Applications of geographic information system (GIS) analysis of lake Uluabat, Environmental Monitoring and Assessment, 188: 331, doi: 10.1007/s10661-016-5332-1.

He J., Balasubramanian R., Burger D.F., Hicks K., Kuylenstierna J.C.I., Palani S., (2011), Dry and wet atmospheric deposition of nitrogen and phosphorus in Singapore, Atmospheric Environment, 45, 2760-2768.

İleri R., Sümer B., Gezbul H., Şenol E., (1997), Sapanca Gölüne mevsimsel besin maddesi yüklenmesinin araştırılması, SAÜ Fen Bilimleri Enstitüsü Dergisi, 1, 1-8.

İleri S., Karaer F., Katip A., Onur S., (2014), Sĭ̆ göllerde su kalitesi değerlendirmesi, Uluabat Gölü örneği, Uludağ Üniversitesi Mühendislik-Mimarlık Fakültesi Dergisi, 19(1), 49-57.

Katip A., (2010), Uluabat Gölü Su Kalitesinin İzlenmesi, Doktora Tezi, Uludağ Üniversitesi Fen Bilimleri Enstitüsü, Bursa.

Katip A., İleri S., Karaer F., Onur S., (2015), Determination of the trophic state of lake Uluabat (Bursa-Turkey), Ekoloji, 24(95), 1-9.

Katip A., Karaer F., İleri S., Onur S.S., (2013), Akçalar (Musa) Deresi azot ve fosfor yüklerinin mevsimsel değişimi ve Uluabat Gölü'ne etkisi, Uludağ Üniversitesi Mühendislik-Mimarlık Fakültesi Dergisi, 18(2), 71-78.

Kazanc1 N., Leroy S., Öncel S., Ileri Ö., Toprak Ö., Costa P., Say1lı S., Turgut C., Kibar M., (2010), Wind control on the accumulation of heavy metals in sediment of Lake Uluabat, Anatolia, Turkey, Journal of Paleolimnology, 43, 89-110.

Kurtoglu S., Ozengin N., Elmaci A., Baskaya H.S., (2015), Monitoring of Sediment Quality and Nutrients Dynamics of Lake Uluabat, Turkey, J. Biol. Environ. Sci., 9(25), 11-19.

Loague K., Corwin D.L., (2005), Point and nonpoint source pollution., Encyclopedia of Hydrological Sciences (Anderson M.G., Ed.), John Wiley \& Sons, New York.

Pejman A.H., Nabi Bidhendi G.R., Karbassi A.R., Mehrdadi N., Esmaeili Bidhendi M., (2009), Evaluation of spatial and seasonal variations in surface water quality using multivariate statistical techniques, Int. J. Environ. Sci. Tech., 6(3), 467-476.

Salihoglu G., Karaer F., (2004), Ecological risk assessment and problem formulation for Lake Uluabat, a Ramsar Site in Turkey, Environmental Management, 33, 899-910. 
Sarmaş1k S., Karaer F., Katip A., Ileri S., Aksoy E., (2011), Assessment of some heavy metals in Lake Uluabat water and sediment using geographic information system, 9. National Environmental Engineering Congress, 05-08 October, Samsun, Turkey.

Singh A., Srivastava P.C., Srivastava P., (2008), Relationships of heavy metals in natural lake waters with physico-chemical characteristics of waters and different chemical fractions of metals in sediments, Water Air Soil Pollution, 188, 181-193.

Şengül F., Müezzinoğlu A., (2001), Çevre Kimyası, Dokuz Eylül Üniversitesi Mühendislik Fak. Yayınları, İzmir, ss 66-74.

Turan F., Ülkü G., (2013), Gökpınar ve Çürüksu Çayları'nın kirlilik parametre ve yüklerinin izlenmesi, Pamukkale Üniversitesi Mühendislik Bilimleri Dergisi, 19(3), 133-144.

Yalçın G., Selçuk O., Şentürk E., (2018), Bursa İli Mustafakemalpaşa İlçesi tarım arazilerinde kapitalizasyon oranının tespiti, Afyon Kocatepe Üniversitesi Fen ve Mühendislik Bilimleri Dergisi, 18(2018), 548-560.

Zeybek M., Kalyoncu H., (2016), Kargı Çayı (Antalya, Türkiye) su kalitesinin fizikokimyasal parametrelere göre belirlenmesi, Ege Journal of Fisheries and Aquatic Sciences, 33(3), 223-231.

Xu F.L., Tao S., Dawson R.W., Xu Z.R., (2003), The distuributions and effects of nutrients in the sediments of a shallow eutrophic Chinese lake, Hydrobiologia, 429: 85-93. 